\title{
BAIRRO DE SANTANA: PERMANÊNCIAS E RUPTURAS NA APROPRIAÇÃO E PERCEPÇÃO DO ESPAÇO EM SÃO JOSÉ DOS CAMPOS DE 1980 A 2010
}

Charles de Lima ${ }^{1}$

\author{
Maria das Graças Sandi Magalhães²
}

\begin{abstract}
Resumo: Este artigo investiga as relações entre espaço e memória em São José dos Campos, mais especificamente, o bairro de Santana. Diferenciando-se dos demais, o bairro não passou pelo processo de verticalização que afetou boa parte da cidade. O congelamento do seu núcleo poderia ser o responsável pela permanência de sociabilidades e usos do espaço que se distanciam do modelo de cidade mundial proposto como uma das representações para a São José dos Campos do século XX.
\end{abstract}

Palavras-chave: Bairro de Santana; Percepção do espaço; Memória joseense; Urbanismo; Ego história.

\footnotetext{
1 Docente, Ensino Básico/Escola Estadual João Cursino; Docente, Faculdade da Terceira Idade/Universidade do Vale do Paraíba, Brasil. charlesdelimah@gmail.com.

2 Docente, Fisioterapia, Pedagogia/Faculdade Anhanguera de São José dos Campos, Brasil. maria.sandi@anhanguera.com.
} 